\title{
Erratum to: Giovanni Verga (1879-1923), author of a pioneering treatise on pituitary surgery: the foundations of this new field in Europe in the early 1900s
}

\author{
José M. Pascual ${ }^{1} \cdot$ Lorenzo Mongardi $^{2} \cdot$ Ruth Prieto $^{3} \cdot$ Inés Castro-Dufourny $^{4}$. \\ María Rosdolsky $^{5} \cdot$ Sewan Strauss $^{6} \cdot$ Rodrigo Carrasco $^{7} \cdot$ Eduard Winter $^{8} \cdot$ Paolo Mazzarello $^{9}$
}

Published online: 16 June 2017

(C) Springer-Verlag GmbH Germany 2017

\section{Erratum to: Neurosurgical Review \\ DOI 10.1007/s10143-017-0864-6}

Figures 4 and 5 caption was reversed in the original published version of this article. Correct captions should be:

Fig. 4 a Lothar Ritter von Frankl-Hochwart (1862-1914), neurologist at Vienna University, expert in the clinical and pathological diagnosis of pituitary tumors, who worked in

The online version of the original article can be found at http://dx.doi.org/ 10.1007/s10143-017-0864-6

José M. Pascual

jmpasncj@hotmail.com

1 Department of Neurosurgery, La Princesa University Hospital, C/ Diego de León 62, 28006 Madrid, Spain

2 Department of Morphology, Surgery and Experimental Medicine, University of Ferrara, Ferrara, Italy

3 Department of Neurosurgery, Puerta de Hierro University Hospital, Madrid, Spain

4 Department of Endocrinology, Sureste University Hospital, Madrid, Spain

5 Independent Medical Translator, Jenkintown, PA, USA

6 School of Medicine, Technische Universität, Dresden, Germany

7 Department of Neurosurgery, Ramón y Cajal University Hospital, Madrid, Spain

8 Anatomical Pathology Collection in the Narrenturm-NHM, Vienna, Austria

9 Department of Brain and Behavioral Sciences and History Museum, University of Pavía, Pavía, Italy collaboration with Alfred Fröhlich, Jakob Erdheim, and Anton von Eiselsberg. b Jakob Erdheim (1874-1937), Viennese pathologist who defined the category of hypophyseal duct tumors (craniopharyngiomas). c Pathological sample of a pituitary adenoma which breaks through the floor of the sella turcica. From Verga G: La Patologia Chirurgica dell'Ipofisi, 1911. d Specimen of a large solid cystic "tumor hypophyseos," probably a hypophyseal duct tumor, stored in 1837 in the Pathologic-Anatomical Collection of Vienna, currently housed at the Narrenturm (Fool's Tower). e Squamous cell nests identified by Jakob Erdheim as the remnants of the hypophyseal duct and the origin of craniopharyngiomas (yellow arrows). From Erdheim, 1904. f Macroscopic appearance of the papillary variant of hypophyseal duct tumor (craniopharyngioma, growing primarily at the level of the third ventricle floor, above the intact pituitary gland). From Walker $\mathrm{CB}$ and Cushing H: Arch Ophthalmol 45: 407-437, 1916

Fig. 5 Clinical diagnosis of pituitary tumors II. Ophthalmological and radiological signs. a Campimetric exams performed on Horsley's pituitary case I, showing the bitemporal hemianopsia caused by a macroadenoma. b Bilateral optic neuritis (papilledema), of greater intensity on the right side, caused by an intracranial tumor, as pictured by Sir Victor Horsley. From Horsley: Br Med J 2: 411-423, 1906. c Lateral skull radiograph of Horsley's patient number X, taken by Dr. Worral, showing enlargement and excavation of the sella turcica and opaque suprasellar shadows corresponding to eggshell calcifications (white arrows), caused by a large craniopharyngioma. a, c From Verga G: La Patologia Chirurgica dell'Ipofisi, 1911 